\title{
Comparative Study of Short Term Outcome of Laparoscopically Assisted versus Totally Laparoscopic Right Colectomy for Right Sid- ed Cancer Colon
}

\author{
Mohamed Elnagar, MD, MRCS; Dina Hany, MD \\ General Surgery Department, Faculty of Medicine, Ain Shams University, Egypt
}

Introduction: Colorectal cancer (CRC) is the third most common cancer in men and second in women worldwide. It is one of the leading causes of cancer death all over the world. Right-sided colon cancer represents approximately $15 \%$ of all cases of CRC. This study was designed to compare the short-term surgical outcomes of laparoscopic-assisted right colectomy (LARC) and totally laparoscopic right colectomy (TLRC) for right sided cancer colon.

Aim of the study: This study was designed to show whether there was any advantage or disadvantage between LARC and TLRC for right sided cancer colon as regard the short term surgical outcomes.

Patients and methods: A consecutive series of 40 patients underwent elective surgery for right-sided colon cancer from April 2014 to October 2015 in Ain Shams University hospitals, Cairo, Egypt and in Al Hamadi hospital, Riyadh, Saudi Arabia. Patients were treated by laparoscopic right colectomy through a medial to lateral approach. In 20 patients a TLRC was performed and in 20 patients LARC was performed. Perioperative care plan, operative steps and surgical instrumentations were standardized. Data on the patients' demographics, disease features, operative details and follow up were recorded and analyzed.

Results: There was no significant difference in term of demographic characteristics, co-morbidities, site of tumor and stage of disease between the two groups. There were 3 cases of conversion to laparotomy. Median operative time (179.7 \pm 16.95 minutes versus $179.85 \pm 17.16$ minutes; not significant (NS)) and estimated blood loss $(67 \pm 16.73 \mathrm{ml}$ versus $65.25 \pm 16.42 \mathrm{ml}$; NS) were statistically not significant in both groups. Timing of first defecation ( $2.75 \pm 0.79$ days versus $2.6 \pm 0.75$ days; NS) and length of hospital stay (4.85 \pm 0.81 days versus $4.7 \pm 1.8$ days; NS) were statistically not significant. A significantly longer length of skin incision characterized LARC group compared with TLRC group $(6.3 \pm 0.99 \mathrm{~cm}$ versus $5.4 \pm 0.76 ; P$ $0.0016)$. Both groups achieved an adequate number of lymph nodes harvested $(15.6 \pm 1.19$ versus $16.8 \pm 1.5$ nodes; P 0.008) and oncological resection of the tumor (proximal margin $9.1 \pm 3.22 \mathrm{~cm}$ versus $9.55 \pm 2.8 \mathrm{~cm}$; NS with distal margin $11.2 \pm 2.35 \mathrm{~cm}$ versus $12.4 \pm 2.3 \mathrm{~cm}$; NS). Post-operative complications were statistically comparable in both groups. No readmission within 30 days of discharge was observed.

Conclusions: Meanwhile most surgeons prefer LARC because it's less technically demanding than TLRC. Both are feasible and safe techniques, with comparable results as regard operative time, preservation of oncologic principles and post operative short-term outcome. Yet, TLRC is superior regarding specimen extraction in both the length and site of skin incision required for specimen extraction.

Key words: Laparoscopically assisted, totally laparoscopic, right colectomy, cancer colon.

\begin{abstract}
Introduction
Colorectal cancer (CRC) is the third most common cancer in men and second in women worldwide. ${ }^{1-3}$ Right-sided colon cancer represents approximately $15 \%$ of all cases of CRC, mostly in the seventh decade of age. ${ }^{1}$
\end{abstract}

Large randomized trials have demonstrated oncologically equivalent outcomes for laparoscopic and open colon resection. ${ }^{4-7}$ Laparoscopy has the additional benefits of improved postoperative recovery, reduced analgesia requirements and shorter length of hospital stay. ${ }^{4,6,8-10}$
There is wide variation among laparoscopic colon resection techniques, including the approach for mobilization (medial-to-lateral versus lateral-tomedial) and the extent of intracorporeal vessel ligation, bowel division or anastamosis. ${ }^{4,5,9}$

Various terminologies have been used to describe the different approaches. The term laparoscopicassisted colectomy encompasses procedures in which a variable portion of the dissection and mobilization is performed intracorporeally followed by exteriorization of the bowel for the extracorporeal anastamosis (EA). Alternatively, a 
totally laparoscopic colectomy refers to a procedure in which the entire mobilization, resection and anastomosis is performed intracorporeally before specimen extraction. ${ }^{7,8,11}$ The literature is limited comparing outcomes between the different surgical techniques in laparoscopic colon resections. ${ }^{12}$ Reports regarding this technique were scanty in comparison with left colectomies or rectal resections, probably due to the technical challenge of this procedure. ${ }^{13,14}$

A recent survey by Jamali et al. on 35 experienced laparoscopic colorectal surgeons concluded that laparoscopic right colectomy was more challenging than sigmoid resection. In addition, the level of difficulty increased significantly from LARC to TLRC, perhaps explaining why most surgeons today don't perform this procedure with ICA. ${ }^{15}$

However, Laparoscopic-assisted colectomy (LAC) technique limits the ability to choose an extraction site, which is usually a small midline incision. In addition, problems with intestinal alignment after extraction are known to occur. A completely intracorporeal anastomosis (IA) may reduce the likelihood or intestinal twists and offers the possibility of using any abdominal location for specimen extraction. ${ }^{12}$

This study was designed to compare the short term surgical outcomes of LARC and TLRC for right sided cancer colon.

\section{Patients and methods}

Between April 2014 to October 2015, a consecutive series of 40 patients underwent laparoscopic right colectomy for cancer at Ain shams university hospitals, Cairo, Egypt and in Al Hamadi hospital, Riyadh, Saudi Arabia. 20 patients were treated by a LARC with ileo-colic EA, while 20 patients were treated by a TLRC with IA, the choice of treatment was random. We included all patients with non metastatic right sided cancer colon including those with cardiovascular and metabolic comorbidity, and obese patients (body mass index $>30 \mathrm{~kg} / \mathrm{m} 2$ ) too. Patients with contraindication to laparoscopy, patients with benign colorectal diseases and emergency operations were excluded.

Preoperative data included demographics, body mass index (BMI), American Society of Anesthesiologists (ASA) score and surgical history.

Operative data included site of the tumor (cecum, right colon and hepatic flexure), operative procedure, conversion, operative time, estimated blood loss (EBL), number of stapler cartridge, intraoperative complications, site of specimen extraction and length of skin incision. Postoperative data included intestinal sounds, time to first defecation, postoperative complications, reoperation, ICU admission, length of hospital stay and 30 days readmission. Oncological outcome included proximal and distal margins, number of lymph nodes harvested and pathologic features (staging according to TNM).

All data were recorded in a specific database and analyzed. Preoperative colonoscopy and biopsy were done for all patients. All patients had pelviabdominal CT with contrast. No patient underwent mechanical bowel preparation.

For tumor localization, we depended on the CT finding and colonoscopic assessment and intraoperative assessment. Indian ink tattooing was not done. All patients were given general anesthesia. Prophylactic broad-spectrum intravenous antibiotics ( $3^{\text {rd }}$ generation cephalosporin) and low molecular weight heparin were administrated one hour prior to induction of anesthesia. A nasogastric tube and a urinary catheter were placed after induction of general anesthesia in all cases. We used a standardized 4-5 ports medial-to-lateral approach summarized in the following steps:

\section{Surgical technique}

There were general steps done in both procedures in the form of: The patient was placed in a supine position with the right arm abducted and the left arm adducted. The surgeon, camera-holder and second assistant stood on the left side of the patient. During the procedure the operating bed was placed in Trendelenburg's position and tilted toward the left.

A $10 \mathrm{~mm}$ supra umbilical port was inserted via Hasson's technique for placement of 30 degree camera. Pneumoperitoneum was established. Peritoneal inspection was then done to evaluate operability and exclude unexpected metastasis. A $12-\mathrm{mm}$ port and a $10 \mathrm{~mm}$ port were placed in left hypocondrium and left iliac fossa lateral to the rectus muscle respectively. A fourth $5-\mathrm{mm} / 10 \mathrm{~mm}$ port was placed in the epigastrium. Occasional $5 \mathrm{~mm} / 10 \mathrm{~mm}$ port was placed suprapubic at the midline.

We proceeded to inspect the right colon and detect the tumor. The greater omentum was moved cranially and the small intestine was placed on the left side of the abdomen. The right colon was then stretched upwards and towards the right lower quadrant exposing the ileo-colic pedicle, supported by upward traction of the transverse colon.

After the identification of the ileo-colic vessels, high ligation and division was performed close to 
their origin at the level of duodenum by Endoclips. Further dissection of colon and mesentery was done using harmonic device.

Mesenteric lymphadenectomy was performed from the origin of ileo-colic vessels in a cranial direction along the superior mesenteric vein (SMV) to the origin of the Henle's gastro-colic trunk, and caudally toward the terminal ileum. The right ureter and gonadic vessels were identified. Caudo-cranial dissection of Toldt's white line from the Gerota's fascia, passing at the level of the lower duodenal part above the fascia of Fredet was done.

The right colic vessels were isolated and divided when present. Then pulling up the transverse colon, its mesentery was dissected from the root and the right branches of the middle colic vessels were identified and dissected by Endoclips.

The complete section of the ileal mesentery and the division of the Tuffier's ligaments and the last caecal adhesions allowed a full mobilization of the right colon. So we proceeded with the resection and anastomosis which varied according to the procedure.

\section{Laparoscopic-assisted right colectomy (LARC)}

A transverse right hypochondrial incision was done, the right colon was exteriorized, terminal ileum and transverse colon were divided. Next steps were common to open ileo-colic anastomosis. We performed a side-to-side isoperistaltic anastomosis by linear open GIA (Figure 1). Then the bowel was replaced into the abdomen for the laparoscopically final check.

Totally-laparoscopic right colectomy (TLRC)
In TLRC, transverse colon and terminal ileum were laparoscopically transected by a $3.5-\mathrm{mm}$ blueand $2.5-\mathrm{mm}$ white-load linear stapler respectively. After terminal ileum and transverse colon were alienated, we performed both the enterotomy and the colotomy on the antimesenteric side.

An intracorporal side-to-side ileo-colic anastomosis was made by a 3.5-mm blue-load linear laparoscopic stapler (Figure 2), and the enterotomy was closed by a single layer running absorbable vicryl suture (Figure 3). The mesenteric gap was closed by continuous absorbable vicryl suture. A Pfannsteil incision is performed for specimen extraction. Drains were used routinely in all patients. Nasogastric tube was removed before recovery from anethesia, urinary catheter was removed after complete recovery from anesthesia and all patients were mobilized very early at the day of operation. Patients started oral fluid intake when having audible intestinal sounds. Criteria for the discharge included absence of symptoms, removal of drain, tolerance to a full solid diet without restrictions and passage of stools. All adverse events that occurred within 30 days after surgery were considered complications. The term anastomotic leakage defined all conditions with clinical or radiological anastomotic dehiscence, with or without the need for surgical revision.

The short-term follow-up was conducted at 7, 14 and 30 days after discharge.

\section{Statistical analysis}

Continuous variables were expressed as mean \pm standard deviation and analyzed with the Student $t$ test. Categorical ones were expressed as percent value and analyzed with Fischer test or Chi-square test, where appropriate. $\mathrm{P}<0.05$ was

Table 1: Demographics and patients' related data

\begin{tabular}{lccc}
\hline Variables & LARC & TLRC & P value \\
\hline Number of patients & 20 & 20 & \\
age & $44.2 \pm 13.92$ & $46 \pm 14.16$ & 0.694981 (NS) \\
Sex M:F & $13: 7$ & $11: 9$ & $0.52(\mathrm{NS})$ \\
BMI & $34.35 \pm 7.98$ & $34.05 \pm 6.98$ & 0.899964 (NS) \\
ASA score & & & \\
I & $4(20 \%)$ & $4(20 \%)$ & 1 NS \\
II & $13(65 \%)$ & $14(70 \%)$ & $0.735(\mathrm{NS})$ \\
III & 3 & 2 & $0.632(\mathrm{NS})$ \\
IV & 0 & 0 & \\
V & 0 & 0 & \\
Previous abdominal surgery & $10(50 \%)$ & $12(60 \%)$ & $0.51(\mathrm{NS})$ \\
\hline
\end{tabular}

M: Male, F: Female, BMI: Body Mass Index, ASA: American Society Of Anesthesiologists 
considered statistically significant.

\section{Results}

Demographics and patients' related data are shown in Table 1, there was no significant difference in term of age, sex, BMI, ASA score and previous abdominal surgical history between the two groups.

\section{Operative data}

Operative data are shown in Table 2. Regarding operative data, there was no statistical difference between the two groups as regards the site of tumor and the type of right colectomy done. There were 3 cases of conversion; 2 cases in LARC and 1 case in TLRC (Figure 4). The cause of conversion was severe tumor adhesions which represented difficulty to continue laparoscopically, so we decided conversion to open technique for patients' safety. Median operative time was $(179.7 \pm 16.95$ minutes in LARC versus $179.85 \pm 17.16$ minutes in TLRC; not significant (NS)) and estimated blood loss $(67 \pm 16.73 \mathrm{ml}$ in LARC versus $65.25 \pm 16.42 \mathrm{ml}$ in TLRC; NS) were statistically not significant in both groups (Figure 5). There was no statistically significant difference in number of stapler cartridges used. There was 1 case with intraoperative complication in the form of bleeding in TLRC and this was not statistically significant. A significantly longer length of skin incision characterized LARC group compared with TLRC group $(6.3 \pm 0.99 \mathrm{~cm}$ versus 5.4 \pm 0.76 ; P 0.0016) (Figure 6).

Table 2: Operative data

\begin{tabular}{lccc}
\hline Variables & LARC & TLRC & P Value \\
\hline Site of the tumor & & & \\
Cecum & $13(65 \%)$ & $15(75 \%)$ & $0.49(\mathrm{NS})$ \\
Right colon & $5(25 \%)$ & $4(20 \%)$ & $0.7(\mathrm{NS})$ \\
Hepatic flexure & $2(10 \%)$ & $1(5 \%)$ & $0.548(\mathrm{NS})$ \\
Operative procedure & & & \\
Right hemicolectomy & $18(90 \%)$ & $19(95 \%)$ & $0.548(\mathrm{NS})$ \\
Extended right hemicolectomy & $2(10 \%)$ & $1(5 \%)$ & $0.548(\mathrm{NS})$ \\
Conversion & $2(10 \%)$ & $1(5 \%)$ & $0.548(\mathrm{NS})$ \\
Operative time (minutes) & $179.7 \pm 16.95$ & $179.85 \pm 17.16$ & $0.978(\mathrm{NS})$ \\
Estimated blood loss (ml) & $67 \pm 16.73$ & $65.25 \pm 16.42$ & $0.74(\mathrm{NS})$ \\
Number of stapler cartridge used & $3.7 \pm 0.47$ & $3.75 \pm 0.44$ & $0.7314(\mathrm{NS})$ \\
Intraoperative complications & $0(0 \%)$ & $1(5 \%)$ & $0.311(\mathrm{NS})$ \\
Length of skin incision $(\mathrm{cm})$ & $6.33 \pm 0.99$ & $5.38 \pm 0.76$ & 0.00157 significant \\
\hline
\end{tabular}

\section{Postoperative data}

Postoperative data are summarized in Table 3. There was no statistically significant difference between both groups in first time of audible intestinal sounds and start of oral intake. Time for first defecation (2.75 \pm 0.79 days in LARC versus $2.6 \pm 0.75$ days in TLRC; NS) was statistically not significant (Figure 7). Total number of patients with postoperative complications was not significant (Figure 8). in LARC, 9 patients had postoperative complications; 3 patients had both chest and wound infection together, 4 patients had wound infection and 2 patients had chest infection. In TLRC, 6 patients had postoperative complications; 3 patients had both chest and wound infection, 2 patients had chest infection only and 1 patient had chest and wound infection with intestinal leakage. There was only 1 case of intestinal leakage in TLRC for which the patient underwent re-laparoscopy and exteriorization of both ends as a stoma. Cases admitted to the ICU were not significant in both groups. All were admitted under observation because of history of cardiac disease and all were discharged after 24 hours. Length of hospital stay ( $4.85 \pm 0.81$ days in LARC versus $4.7 \pm 1.8$ days in TLRC; NS) wasnotsignificant. Follow up at 7,14 and 30 days showed no significant complication nor readmission.

\section{Oncological outcome data}

Oncological outcome is summarized in Table 4. Resection margins were comparable in both groups; proximal margin was $9.1 \pm 3.22 \mathrm{~cm}$ in LARC versus $9.55 \pm 2.8 \mathrm{~cm}$ in TLRC (NS) with distal margin $11.2 \pm 2.35 \mathrm{~cm}$ in LARC versus $12.4 \pm 2.3 \mathrm{~cm}$ 
in TLRC (NS). Pathologic features (staging according to TNM) are comparable in both groups. Although number of lymph nodes harvested are

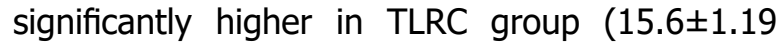

versus $16.8 \pm 1.5$ nodes; $P$ 0.008), yet the number of lymph nodes harvested was adequate in both groups (Figure 9).

Table 3: Postoperative data

\begin{tabular}{lccc}
\hline Variables & LARC & TLRC & P Value \\
\hline Intestinal sounds/ Start of oral intake (days) & $1.85 \pm 0.67$ & $1.6 \pm 0.6$ & 0.22 (NS) \\
Time to first defecation (days) & $2.75 \pm 0.79$ & $2.6 \pm 0.75$ & 0.542 (NS) \\
Postoperative complications & $9(45 \%)$ & $6(30 \%)$ & 0.327 (NS) \\
Chest infection & $5(25 \%)$ & $6(30 \%)$ & 0.723 (NS) \\
Wound infection & $7(35 \%)$ & $4(20 \%)$ & 0.288 (NS) \\
Intestinal leakage & $0(0 \%)$ & $1(5 \%)$ & 0.311 (NS) \\
Removal of drain (days) & $4.25 \pm 0.72$ & $4.2 \pm 1.47$ & 0.892 (NS) \\
Reoperation & $0(0 \%)$ & $1(5 \%)$ & 0.311 (NS) \\
ICU admission & $1(5 \%)$ & $4.7 \pm 1.8$ & 0.548 (NS) \\
Length of hospital stay (LOS) (days) & $4.85 \pm 0.81$ & $4.7 \pm 1.8$ & 0.737 (NS) \\
\hline
\end{tabular}

Table 4: Oncological outcome

\begin{tabular}{lccc}
\hline Variables & LARC & TLRC & P value \\
\hline Proximal margin & $9.1 \pm 3.226$ & $9.55 \pm 2.8$ & 0.640276 (NS) \\
Distal margin & $11.2 \pm 2.35$ & $12.4 \pm 2.3$ & 0.111403 (NS) \\
Number of lymph nodes harvested & $15.6 \pm 1.19$ & $16.8 \pm 1.5$ & 0.008 significant \\
TNM staging & & & \\
T1 & 0 & 0 & 0.49 (NS) \\
T2 & $15(75 \%)$ & $13(65 \%)$ & 0.7 (NS) \\
T3 & $4(20 \%)$ & $5(25 \%)$ & 0.548 (NS) \\
T4 & $1(5 \%)$ & $2(10 \%)$ & 1 (NS) \\
N0 & $1(5 \%)$ & $1(5 \%)$ & 0.288 (NS) \\
N1 & $16(80 \%)$ & $13(65 \%)$ & 0.256 (NS) \\
N2 & $3(15 \%)$ & $6(30 \%)$ & \\
M0 & 20 & 20 & 0 \\
M1 & 0 & 0 & \\
\hline
\end{tabular}




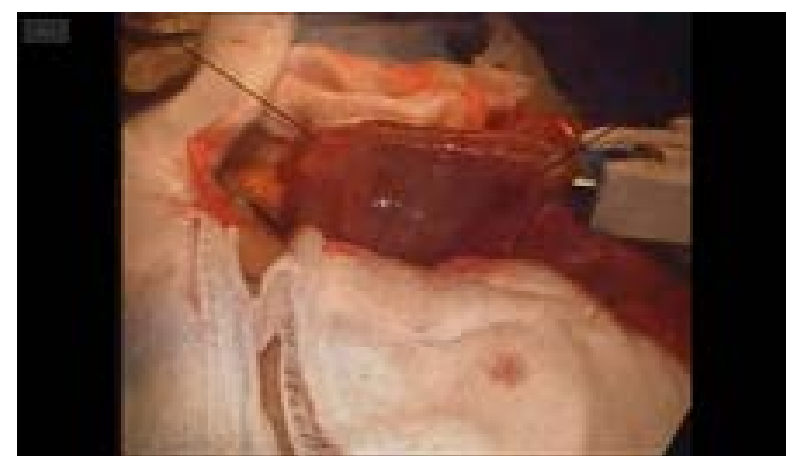

Fig 1: Extracorporeal anastomosis after LARC.

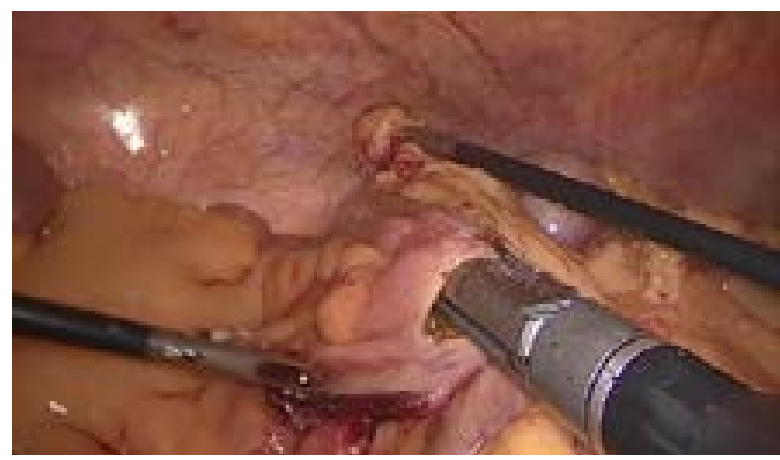

Fig 2: Intracorporeal anastomosis during TLRC.

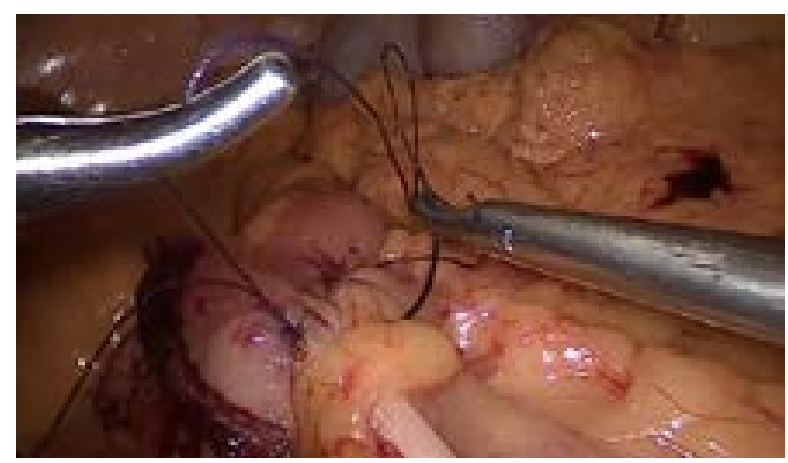

Fig 3: Laparoscopic suturing during TLRC.

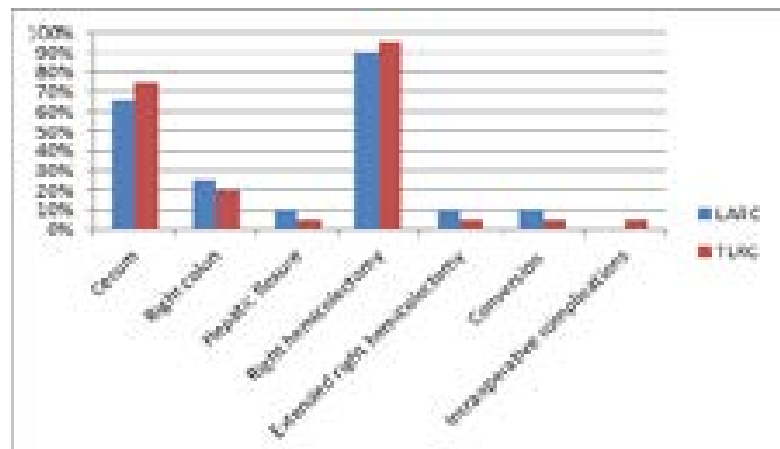

Fig 4: Site of tumor, type of right colectomy, conversion rate and intraoperative complications.

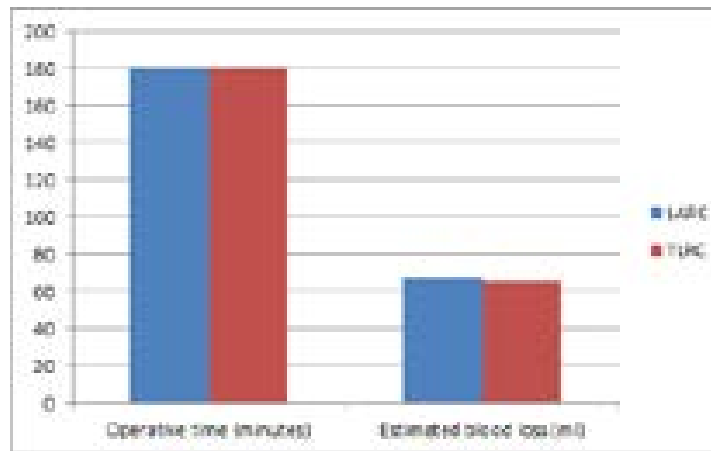

Fig 5: Operative time and estimated blood loss.

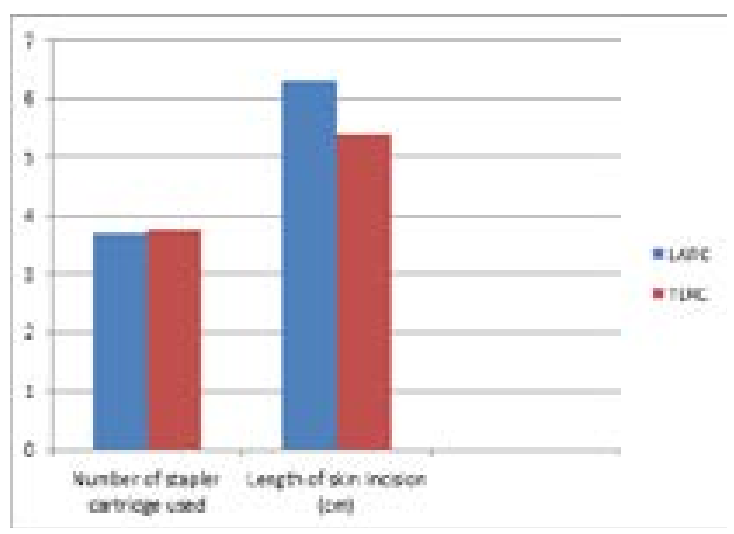

Fig 6: Number of stapler cartridges and length of skin incision.

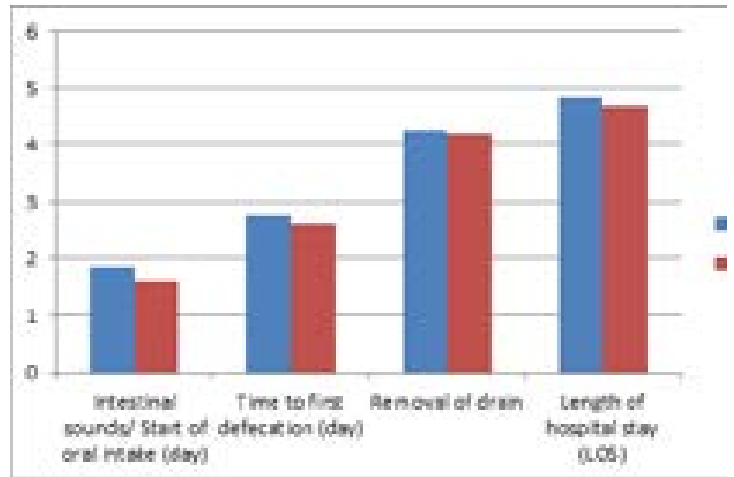

Fig 7: Postoperative data.

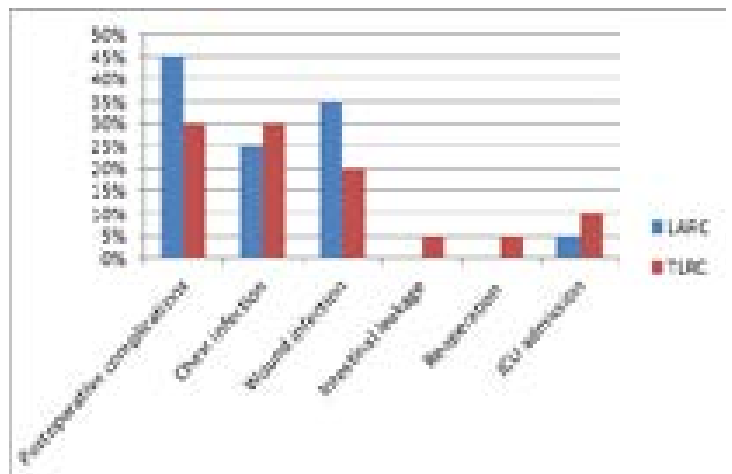

Fig 8: Postoperative complications. 


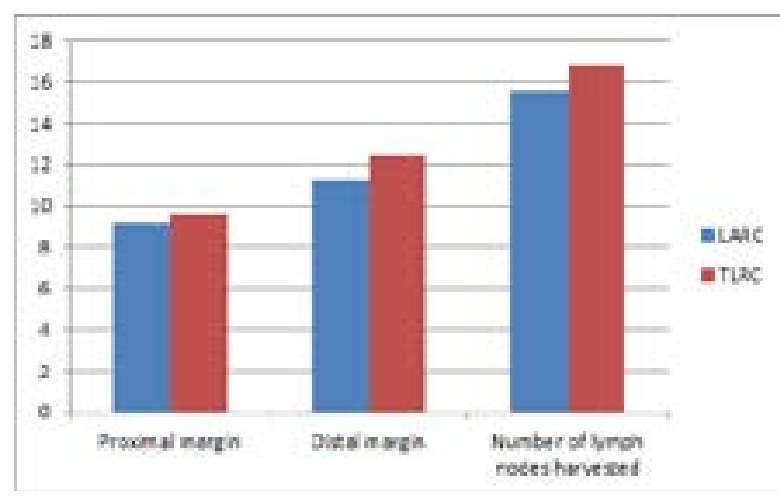

Fig 9: Oncologic outcome.

\section{Discussion}

Laparoscopic colorectal surgery offers both short and long-term benefits compared with open colorectal surgery. These benefits include less postoperative pain, better pulmonary function, less postoperative ileus and shorter LOS. In addition, meta-analysis and randomized controlled trials with level- 1 evidence have demonstrated that laparoscopic colorectal surgery achieves oncological outcomes that are no different from those achieved with the conventional open approach. ${ }^{16-18}$

There were 3 cases of conversion; $10 \%$ in LARC and $5 \%$ in TLRC, which is not significant. The cause of conversion was severe tumor adhesions which represented difficulty to continue laparoscopically, so we decided conversion to open technique for patients' safety.

Guidelines for Laparoscopic Resection of Curable Colon and Rectal Cancer recommended by the Society of American Gastrointestinal and Endoscopic Surgeons (SAGES) stated that inability to adhere to all accepted oncologic principles including appropriate vascular ligation should prompt conversion to an open operation. ${ }^{19}$

In Lee et al study, the conversion rate to open surgery was $8.6 \%$ in the EA group, but none in the IA group ( $p=0.064, N S) .{ }^{10}$ In Chaves et al, conversion rate was $8 \%$ in LARC and $0 \%$ in TLRC. ${ }^{20}$

Our mean operative time was $(179.7 \pm 16.95$ minutes in LARC versus $179.85 \pm 17.16$ minutes in TLRC; not significant (NS)) and estimated blood loss $(67 \pm 16.73 \mathrm{ml}$ in LARC versus $65.25 \pm 16.42 \mathrm{ml}$ in TLRC; NS) were statistically not significant in both groups.

InRoscioetalstudy, meanoperativetime $(186.3 \pm 40.1$ min vs $176.5 \pm 40.0 \mathrm{~min}$; not significant (NS)) and estimated blood loss $(43.3 \pm 89.8 \mathrm{ml}$ vs $31.2 \pm 51.3$ $\mathrm{ml}$; NS) were statistically comparable in both groups. ${ }^{1}$ Lee et al results showed no significant difference in operative time nor estimated blood loss between the 2 groups. ${ }^{10}$ Magistro et al results showed operative time in TLC significantly longer than in LAC (230 vs. $203 \mathrm{~min}) .^{21}$

The largest 4 studies on intracorporeal anastomosis with right colectomies ${ }^{9,22-25}$ reported operative times from 120 minutes to 218 minutes comparing favorably to operative times of 85 minutes to 190 minutes recorded for laparoscopic-assisted colectomies with extracorporeal anastomosis. ${ }^{9,26-31}$

A significantly longer length of skin incision characterized LARC group compared with TLRC group (6.3 $\pm 0.99 \mathrm{~cm}$ versus $5.4 \pm 0.76 ; \mathrm{P} 0.0016)$.

In Roscio et al a significantly longer length of skin incision characterized LARC group compared with TLRC group $(71.0 \pm 13.5 \mathrm{~mm}$ vs $48.2 \pm 10.2 \mathrm{~mm}$; $P$ $<0.001) .{ }^{1}$ Magistro et al results the length of the minilaparotomy was clearly shorter in TLC group $(5.5$ vs. $7.2 \mathrm{~cm}) .^{21}$

Technically, minilaparotomy following ICA has just the purpose to pull out the specimen already resected, while in LARC skin incision might be large enough to allow the pulling out of the right colon and the last ileal loop, their section and anastomosis, avoiding compression of the mesentery. ${ }^{1}$

Meanwhile we could choose any site for specimen extraction in TLRC; we chose a Pfannsteil incision for better cosmosis, yet in LARC, we only had to choose between a right hypochondrial incision and a midline incision; thus we chose a right hypochondrial incision for better cosmosis.

Time for first defecation ( $2.75 \pm 0.79$ days in LARC versus $2.6 \pm 0.75$ days in TLRC; NS) was statistically not significant, length of hospital stay $(4.85 \pm 0.81$ days in LARC versus $4.7 \pm 1.8$ days in TLRC; NS) was not significant.

In Roscio et al, timing of first defecation ( $3.4 \pm 0.9$ dd vs $2.9 \pm 0.9 ; P=0.023$ ) and length of hospital stay $(7.2 \pm 1.3$ dd vs $6.2 \pm 1.1 \mathrm{dd} ; \mathrm{P}<0.001)$ were statistically lower in TLRC cohort. ${ }^{1}$

Total number of patients with postoperative complications was not significant. There was only 1 case of intestinal leakage in TLRC for which the patient underwent re-laparoscopy and exteriorization of both ends as a stoma.

Lee et al results showed no significant difference in complications (intra-abdominal abscess, anastomotic leak, ileus, and wound infection), and length of hospital stay between the 2 groups. ${ }^{10}$ Magistro et al results showed complication rate was similar in both groups, with no case of anastomotic 
dehiscence, two anastomotic bleedings in TLC vs, three in LAC. ${ }^{21}$

TheseriesbyFranklinetal ${ }^{23}$ comparingintracorporeal anastomosis for right colon resections ( $n \_82$ ) with 10 cases with extracorporeal anastomosis showed that intracorporeal approach was found to be safe and feasible with similar operative times and complication rates. These findings are confirmed by Bergamaschi et $\mathrm{al}^{25}$ who recently described the short-term outcomes of 111 intracorporeal right colectomies.

We followed safe oncological principles during our study, and our results were oncological adequate as compared to guidelines established by the 2000 National Cancer Institute (NCI)-sponsored Colon and Rectal Cancer Surgery recommendations for oncologicaly safe colonic resection for curable cancer colon. Although number of lymph nodes harvested are significantly higher in TLRC group $(15.6 \pm 1.19$ versus $16.8 \pm 1.5$ nodes; $P$ 0.008), yet the number of lymph nodes harvested was adequate in both groups.

Guidelines established by the 2000 National Cancer Institute (NCI)-sponsored Colon and Rectal Cancer Surgery Consensus Panel state that the margins of resection for colon cancer are determined by the arterial supply feeding the affected segment of colon. ${ }^{19,32}$ Proximal ligation of vessels supplying tumors, or of multiple feeding vessels when the tumor falls between arterial distributions, should result in adequate proximal and distal resection margins. Lesions should be excised en bloc with oncologically appropriate tumor-free radial margins (R0) to be considered curative. ${ }^{19,33}$ The bowel margins of resection should be at least $5 \mathrm{~cm}$ from the tumor to minimize anastomotic recurrences. A proper lymphadenectomy should extend to the level of the feeding artery. To affect a cure, all lymph nodes should be removed en bloc with the tumorbearing segment of colon. For entry into adjuvant trials for negative lymph nodes, at least 12 lymph nodes must be examined. ${ }^{32}$

\section{Conclusion}

Meanwhile most surgeons prefer LARC because it's lesstechnicallydemandingthan TLRC; which requires high surgical skills for laparoscopic suturing. Both are feasible and safe techniques, with comparable results as regard operative time, preservation of oncologic principles and post operative shortterm outcome. Yet, TLRC is superior regarding specimenextraction in both thelengthandsiteofskin incision required for specimen extraction.

\section{Limitations}

This study has a relatively small sample size. It assesses only short term results with no long term follow up.

\section{References}

1. Roscio F, Bertoglio C, De Luca A, Frattini P, Scandroglio I: Totally laparoscopic versus laparoscopic assisted right colectomy for cancer. International Journal of Surgery 2012; 10: 290-295.

2. Ferlay J, Soerjomataram I, Ervik M, Dikshit R, Eser S, Mathers C, Rebelo M, Parkin DM, Forman D, Bray F: Cancer incidence and mortality worldwide: IARC. Globocan 2012 v1.0, Cancer Base No. 11.

3. Parkin DM, Bray F, Ferlay J, Pisani P: Estimating the world cancer burden: Globocan 2000. Int J Cancer 2001; 94: 153-156.

4. Vergis $A$, Steigerwald $S$, Bhojani FD, Sullivan $\mathrm{PA}$, and Hardy KM: Laparoscopic right hemicolectomy with intracorporeal versus extracorporeal anastamosis: $\boldsymbol{A}$ comparison of short-term outcomes Can J Surg 2015; 58: 63-68.

5. Anania G, Santini M, Scagliarini L, et al: A totally mini-invasive approach for colorectal laparoscopic surgery. World J Gastroenterol 2012; 18: 3869-3874.

6. Chung CC, Ng DC, Tsang WW, et al: Handassisted laparoscopic versus open right colectomy: A randomized controlled trial. Ann Surg 2007; 246: 728-733.

7. Grams J, Tong W, Greenstein AJ, et al: Comparison of intracorporeal versus extracorporeal anastomosis in laparoscopicassisted hemicolectomy. Surg Endosc 2010; 24: $1886-1891$.

8. Erguner I, Aytac E, Baca B, et al: Totally laparoscopic approach for the treatment of right colon cancer: Atechnical critique. Asian $\boldsymbol{J}$ Surg 2013; 36: 58-63.

9. Hellan $M$, Anderson C, Pigazzi A: Extracorporeal versus intracorporeal anastomosis for laparoscopic right hemicolectomy. JSLS 2009; 13: 312-317.

10. Lee KH, Ho J, Akmal $Y$, et al: Short-and long-term outcomes of intracorporeal versus extracorporeal ileocolic anastomosis in laparoscopic right hemicolectomy for colon cancer. Surg Endosc 2013; 27: 1986-1990. 
11. Fabozzi M, Allieta $R$, Contul RB, et al: Comparison of short-and medium-term results between laparoscopically assisted and totally laparoscopic right hemicolectomy: A casecontrol study. Surg Endosc 2010; 24: 20852091.

12. Berends FJ, Kazemier J, Bonjer HJ, Lange JF: Subcutaneous metastases after laparoscopic colectomy. Lancet 1994; 344: 358.

13. Tan WS, Chew MH, Ooi BS, Ng KH, Lim JF, Ho KS, et al: Laparoscopic versus open right hemicolectomy: A comparison of short-term outcomes. Int J Colorectal Dis 2009; 24: 13331339.

14. Tong D, Law WL: Laparoscopic versus open right hemicolectomy for carcinoma of the colon. JSLS 2007; 11: 76-80.

15. Jamali FR, Soweid AM, Dimassi H, Bailey C, Leroy J, Marescaux J: Evaluating the degree of difficulty of laparoscopic colorectal surgery. Arch Surg 2008; 143: 762-767.

16. Kuhry E, Schwenk WF, Gaupset $R$, et al: Long-term results of laparoscopic colorectal cancer resection. Cochrane Database Syst Rev 2008; CD003432.

17. Jayne DG, Thorpe HC, Copeland J, et al: Fiveyear follow-up of the Medical Research Council CLASICC trial of laparoscopically assisted versus open surgery for colorectal cancer. $\boldsymbol{B r} \boldsymbol{J}$ Surg 2010; 97: 1638-1645.

18. Bonjer $\mathrm{HJ}$, Hop WC, Nelson $\mathrm{H}$, et al: Laparoscopically assisted vs open colectomy for colon cancer: A meta-analysis. Arch Surg 2007; 142: 298-303.

19. Zerey M, Hawver LM, Awad Z, Stefanidis D, Richardson W, Fanelli RD: SAGES evidencebased Guidelines for Laparoscopic Resection of Curable Colon and Rectal Cancer. Surg Endosc 2013; 27: 1-10.

20. Chaves JA, Idoate $C P$, Fons JB, Oliver $M B$, Rodríguez NP, Delgado AB, et al: A case-control study of extracorporeal versus intracorporeal anastomosis in patients subjected to right laparoscopic hemicolectomy. Cir Esp 2011; 89: 24-30.

21. Magistro C, Lernia SD, Ferrari G, Zullino A, Mazzola M, De Martini P, De Carli S, Forgione A, Bertoglio CL, Pugliese R: Totally laparoscopic versus laparoscopic-assisted right colectomy for colon cancer: Is there any advantage in short-term outcomes? A prospective comparative assessment in our center. Surg Endosc 2013; 27: 2613-2618.

22. Casciola L, Ceccarelli G, Di Zitti L, et al: Laparoscopic right hemicolectomy with intracorporeal anastomosis. Technical aspects and personal experience. Minerva Chir 2003; 58: 621-627.

23. Franklin ME, Gonzalez JJ, Miter DB, et al: Laparoscopic right hemicolectomy for cancer: 11-year experience. Rev Gastroenterol Mex 2004; 69: 65-72.

24. Raftopoulos I, Courcoulas AP, Blumberg D: Should completely intracorporeal anastomosis be considered in obese patients who undergo laparoscopic colectomy for benign or malignant disease of the colon? Surgery 2006; 40: 675682.

25. Bergamaschi R, Schochet E, Haughn C, Burke M, Reed JF, Arnaud JP: Standardized laparoscopic intracorporeal right colectomy for cancer: short-term outcome in 111 unselected patients. Dis Colon Rectum 2008; 51: 1350 -1355 .

26. The Clinical Outcomes of Surgical Therapy Study Group: A comparison of laparoscopically assisted and open colectomy for colon cancer. N Engl J Med 2004; 350: 2050-2059.

27. Baca I, Perko Z, Bokan I, et al: Technique and survival after laparoscopically assisted right hemicolectomy. Surg Endosc 2005; 19: 650655.

28. Kaiser AM, Kang JC, Chan LS, Vukasin P, Beart RW: Laparoscopic-assisted vs. open colectomy for colon cancer: A prospective randomized trial. J Laparoendosc Adv Surg Tech A 2004; 14: 329-334.

29. Leung $\mathrm{KL}$, Meng $\mathrm{WC}$, Lee JF, Thung $\mathrm{KH}$, Lai PB, Lau WY: Laparoscopic-assisted resection of right-sided olonic carcinoma: A case-control study. J Surg Oncol 1999; 71: 97-100.

30. Lezoche $E$, Feliciotti F, Paganini AM, Guerrieri M, De SA, Minervini S, Campagnacci R: Laparoscopic vs open hemicolectomy for colon cancer. Surg Endosc 2002; 16: 596-602.

31. Senagore AJ, Delaney CP, Brady KM, Fazio VW: Standardized approach to laparoscopic right colectomy: Outcomes in 70 consecutive cases. J Am Coll Surg 2004; 199: 675- 679. 
32. Nelson H, Petrelli N, Carlin A, et al: Guidelines 2000 for colon and rectal cancer surgery. J Natl Cancer Inst 2001; 93: 583-596.
33. Ishihara $\mathrm{S}$, Watanabe $\mathrm{T}$, Nagawa $\mathrm{H}$ : Intraoperative colonoscopy for stapled anastomosis in colorectal surgery. Surg Today 2008; 38: 1063-1065. 